
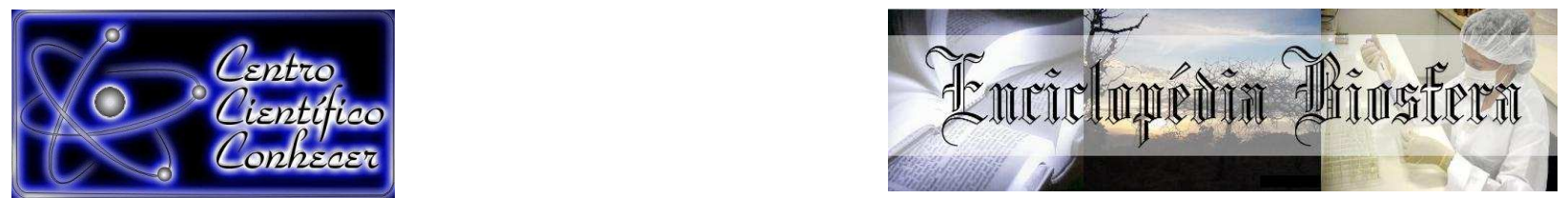

\title{
AVALIAÇÃO DE METODOLOGIAS PRÁTICAS DE BAIXO CUSTO NO ENSINO SOBRE VÍRUS, BACTÉRIAS, FUNGOS E PROTISTAS
}

\author{
Lidiane da Silva Nascimento , Cláudia Maria Reis Raposo Maciel², $^{2}$ \\ Alaor Maciel Júnior ${ }^{2}$ \\ ${ }^{1}$ Bióloga, discente do curso de doutorado em Biologia Celular e Estrutural da Universidade \\ Federal de Viçosa, Viçosa, Brasil (lidiane.nascimento1@hotmail.com). \\ ${ }^{2}$ Professor Titular da Universidade Estadual do Sudoeste da Bahia, Itapetinga, Brasil \\ Recebido em: 03/10/2016 - Aprovado em: 21/11/2016 - Publicado em: 05/12/2016 \\ DOI: 10.18677/EnciBio_2016B_107
}

\begin{abstract}
RESUMO
Um dos maiores desafios no ensino de ciências é a aplicação de aulas práticas, uma vez que fatores como falta de material e laboratório, elevado número de alunos em sala de aula e a carga horária dos docentes são relatados como empecilhos para o desenvolvimento destas práticas. Diante do exposto, objetivou-se avaliar o aprendizado dos discentes após a inserção das práticas durante o ensino de vírus, bactérias, fungos e protistas. Foram analisadas duas turmas da $6^{\underline{a}}$ serie ( $7^{\circ}$ ano) do Ensino Fundamental II de uma escola pública municipal de Itapetinga, Bahia, totalizando 64 alunos. Uma turma foi submetida às aulas teóricas e práticas e a outra apenas as aulas teóricas. Para a coleta de dados foi aplicado um questionário prévio e outro após o término de cada conteúdo. Os dados percentuais entre as duas turmas foram analisados por meio do teste exato de Fisher $(p<0,05)$. Os resultados indicaram que a turma com aulas teóricas e práticas soube melhor caracterizar e diferenciar vírus, bactérias e fungos quando comparada à turma sem aulas práticas. Contudo, no ensino de protistas não houve diferença entre as turmas. Com isto, foi possível concluir que a inserção das aulas práticas contribui para o melhor desempenho dos alunos.
\end{abstract}

PALAVRAS CHAVE: aulas práticas, conhecimento, ensino de ciências

\section{ASSESSMENT OF LOW COST PRACTICAL METHODOLOGIES IN TEACHING ABOUT VIRUSES, BACTERIA, FUNGI AND PROTISTS}

\begin{abstract}
One of the major challenges in teaching of Sciences is the application of practical lessons, since factors such as lack of material and laboratory high number of students in the classroom and the workload of teachers are reported as obstacles to the development of these practices. In front of the exposed, it was aimed to evaluate the student learning after the insertion of the practices during the teaching of virus, bacteria, fungi and protists. It was analyzed two groups of 6 th series (7th grade) of elementary school II of a municipal public school of Itapetinga, Bahia, totaling 64 students. One group was subjected to theoretical and practical lessons and the other only theoretical. For data collection was applied a previous survey and another, after the end of each content. The percentage data between the two groups were analyzed using Fisher's exact test $(p<0,05)$. The results indicated that the class with theoretical and practical lessons learned better characterize and differentiate viruses, bacteria and fungi when compared to the group without practical lessons. However, there was no difference between the groups about teaching of protists. Thus, it was
\end{abstract}


concluded that the inclusion of the practical lessons has contributed to the better performance of the students.

KEYWORDS: practical lessons, knowledge, teaching of Sciences

\section{INTRODUÇÃO}

A utilização de métodos de ensino que contribuem no processo de ensinoaprendizagem é um dos constantes desafios na relação entre escola professor e aluno. Dentre metodologias importantes para o ensino, as aulas práticas são consideradas parte fundamental do processo educacional (BRASIL, 1998). Contudo, sua utilização em sala de aula, especificamente no ensino de ciências, ainda é escassa na maior parte das escolas (ANDRADE \& MASSABNI, 2011)

A investigação do uso de aulas práticas em escolas tem sido foco de variados estudos na área da biologia (BOAS \& MOREIRA, 2012; BORGES \& TAUCHEN, 2012). Na maior parte destes estudos, os principais obstáculos apontados para utilização de aulas práticas são a falta de recursos, principalmente do laboratório de Biologia, turmas lotadas e a falta de tempo dos docentes para elaborar estas aulas. O desinteresse por parte dos alunos é também citado, o uso de aulas práticas tem mostrado ser ferramenta útil para contextualização dos conteúdos como também para atrair a atenção dos alunos (EUGÊNIO, 2012), o que demonstra a importância da inserção das mesmas na exposição dos conteúdos a fim de estimular os discentes nas aulas.

Contudo, neste cenário, não se pode negligenciar as dificuldades enfrentadas diariamente pelos docentes, com isso, apontar apenas as falhas no processo de ensino não é algo encorajador. Ao invés disto, é necessário discutir e propor metodologias que façam parte da realidade escolar e que utilizem materiais de fácil acesso para docentes e alunos.

Dentre os diversos assuntos abordados em ciências no ensino fundamental, destacam-se o estudo dos vírus, bactérias, fungos e protistas. Muitos são conhecidos por causar doenças, alguns destes desempenham importantes papéis no meio ambiente e são úteis em diversos processos industriais (TORTORA, 2012). Verifica-se que os discentes têm dificuldade em diferenciar estes grupos, por isso, é necessário o desenvolvimento de abordagens diferenciadas.

Diante do exposto, objetivou-se avaliar o aprendizado dos discentes após a inserção de práticas durante o ensino de vírus, bactérias, fungos e protistas. Os objetivos específicos consistiram em (1) propor aulas práticas com materiais de baixo custo e (2) elaborar um manual de aulas práticas sobre os conteúdos trabalhados.

\section{Local e público alvo}

\section{MATERIAL E MÉTODOS}

Este trabalho foi desenvolvido com discentes da $6^{\underline{a}}$ série ( $7^{\circ}$ ano) de uma instituição da rede pública de Ensino Fundamental II na cidade de Itapetinga, Bahia. Duas turmas foram escolhidas aleatoriamente. Cada turma possuía 32 alunos.

Primeiramente foi realizado um contato prévio com a docente da disciplina de ciências, a fim de requerer seu apoio e auxílio. A metodologia consistiu na inclusão de aulas práticas após as aulas teóricas ministradas pela docente durante os conteúdos referentes aos vírus, bactérias, fungos e protistas. As atividades práticas foram desenvolvidas com a presença e participação da docente. Na turma 1 (T1), as aulas foram teóricas e na turma 2 (T2) as aulas foram teóricas e práticas. As práticas 
utilizaram como ferramentas de apoio: aparelho de DVD, televisão e materiais básicos para a realização das práticas referentes aos conteúdos.

\section{Coleta de dados}

Nas duas turmas foi aplicado um questionário antes de cada conteúdo, com a finalidade de analisar os conhecimentos prévios dos alunos. E no término dos conteúdos foi aplicado outro questionário. Nos dois questionários, as questões foram abertas e consistiram de três principais abordagens: (1) o conceito sobre cada conteúdo, (2) o conhecimento sobre doenças causadas e (3) o conhecimento sobre as medidas de prevenção.

\section{Análise de dados}

Primeiramente, os questionários de cada turma foram tabulados e analisados de acordo com respostas similares ou relacionadas, depois foi calculado 0 percentual. Para comparação dos percentuais foi utilizado o teste exato de Fisher $(p<0,05)$. Após esta análise, os dados foram expostos em um gráfico com a finalidade de comparar o conhecimento prévio e o conhecimento adquirido após as aulas nas duas turmas.

\section{Elaboração do manual de atividades práticas}

Foi confeccionado um manual de atividades práticas sobre vírus, bactérias, fungos e protistas. Este manual continha as metodologias desenvolvidas durante a pesquisa e outras atividades práticas sugeridas. Todas as metodologias apresentadas utilizaram materiais de baixo custo e fácil aquisição. Junto ao manual foi disponibilizado um DVD com os vídeos e as imagens utilizadas nas atividades práticas.

\section{Conceito de vírus, bactérias, fungos e protistas \\ RESULTADOS E DISCUSSÃO}

O conhecimento prévio sobre vírus não diferiu entre as turmas. A turma que recebeu somente aula teórica (T1) e a turma que recebeu aula teoria e prática (T2) relacionaram vírus principalmente às doenças, contudo, não houve diferenciação entre vírus e bactérias (Figura 1A). No questionário final, as duas turmas ainda relacionavam vírus às doenças. Contudo, houve diferença da T2 em relação T1, cerca de $51 \%$ dos discentes conceituaram vírus como sendo microrganismos, com consequente redução da associação com bactérias (8\%), enquanto que na T1 houve aumento da conceituação de vírus como sendo bactérias (40\%) e apenas $9 \%$ dos discentes conceituaram vírus como microrganismos (Figura 1B).

0 que são vírus?

0 que são vírus?

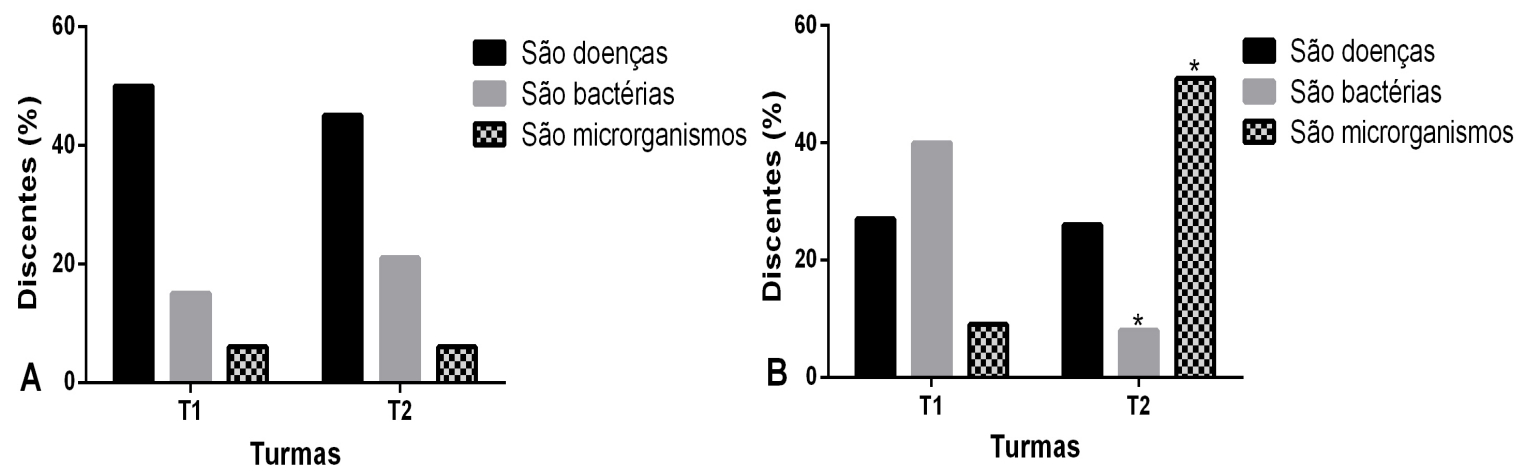

FIGURA 1. Percentual (\%) dos discentes quanto ao conceito de vírus. (A): Questionário inicial e (B) Questionário final. T1=Turma teórica e T2= Turma teórica e prática. 
Quanto ao conceito de bactérias, previamente os discentes relataram que as bactérias eram causadores de doenças 42\% e 35\% respectivamente para T1 e T2. Seguido pela associação com vírus e microrganismos (Figura $2 \mathrm{~A}$ ). No questionário final foi observada diferença da T2 em relação a T1 sobre o conceito de bactérias como microrganismo (52\%) e na redução da associação com vírus (3\%). Na T1, $36 \%$ dos discentes denominaram bactérias como microrganismos e $19 \%$ fizeram associação com vírus (Figura 2B).

Dados positivos com o uso de aulas práticas também foram observados em discentes por BOAS \& MOREIRA (2012) após o uso de métodos diferenciados como palestras, workshops e aulas práticas no ensino sobre microrganismos do solo. Com isto, infere-se que a abordagem prática na T2 pode ter contribuído para a remodelação dos conceitos prévios dos discentes sobre vírus e bactérias.

0 que são bactérias?

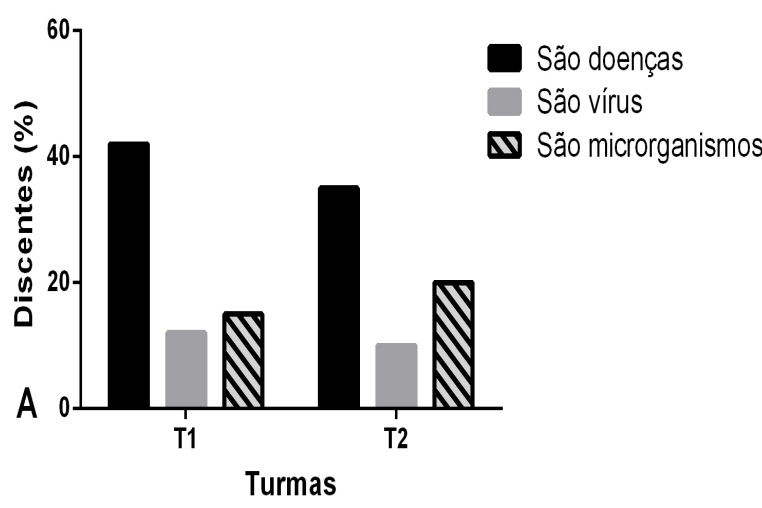

0 que são bactérias?

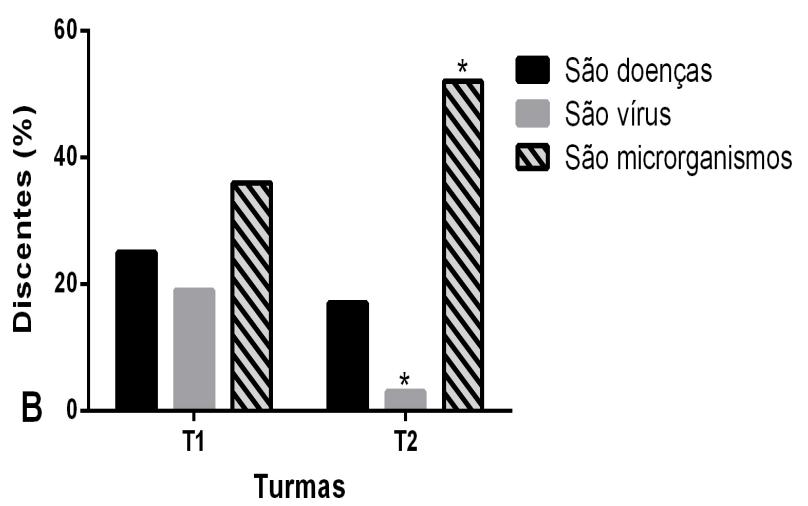

FIGURA 2. Percentual (\%) dos discentes quanto ao conceito de bactérias. (A): Questionário inicial e (B) Questionário final. T1=Turma teórica e T2= Turma teórica e prática.

Em relação ao conceito de fungos, nas duas turmas, houve associação com bactérias e apenas $16 \%$ e $19 \%$ dos discentes, respectivamente da T1 e T2, responderam baseados nos exemplos mais comuns (mofos e bolores). Outras respostas foram dadas em associação com doenças, sem especificá-las. Além disto, foi observado que o conceito de fungos como microrganismos diferiu na T2 $(26 \%)$ em relação a T1 (5\%) (Figura $3 \mathrm{~A})$. No questionário final da T1, o percentual $(48 \%)$ de citação dos nomes de fungos mais comuns (orelha-de-pau, bolor, cogumelo e mofo) aumentou em relação a T2 (23\%). Contudo, nas duas turmas, ainda houve associação dos fungos como sendo bactérias. O uso do termo microrganismo persistiu na T2 e ainda houve diferença para fungos como seres eucariontes, unicelulares ou pluricelulares (20\%) quando comparado a T1 (2\%) (Figura 3B).

O aumento no percentual dos termos eucariontes, unicelulares ou pluricelulares pela T2 pode ter relação com a visualização nas aulas práticas de fungos unicelulares, como as leveduras ou fungos multicelulares como orelha de pau. Outro ponto importante foi o uso do termo eucarionte, uma vez que, ao contrário de vírus e bactérias, os fungos possuem material genético envolvido por membrana, formando o núcleo celular (HICKMAN et al., 2016). Contudo, embora houve melhora de conceituação dos fungos na T2, os discentes ainda apresentaram dificuldade para caracterizar os fungos, associando genericamente às doenças. De fato, o Reino Fungi possui espécies com variadas morfologias e dimensões 
(GUARRO, 2012), o que pode ter dificultado a caracterização das mesmas pelos alunos. Com isto, o desenvolvimento de outras abordagens teóricas e práticas são necessárias para facilitar a distinção destes seres vivos.
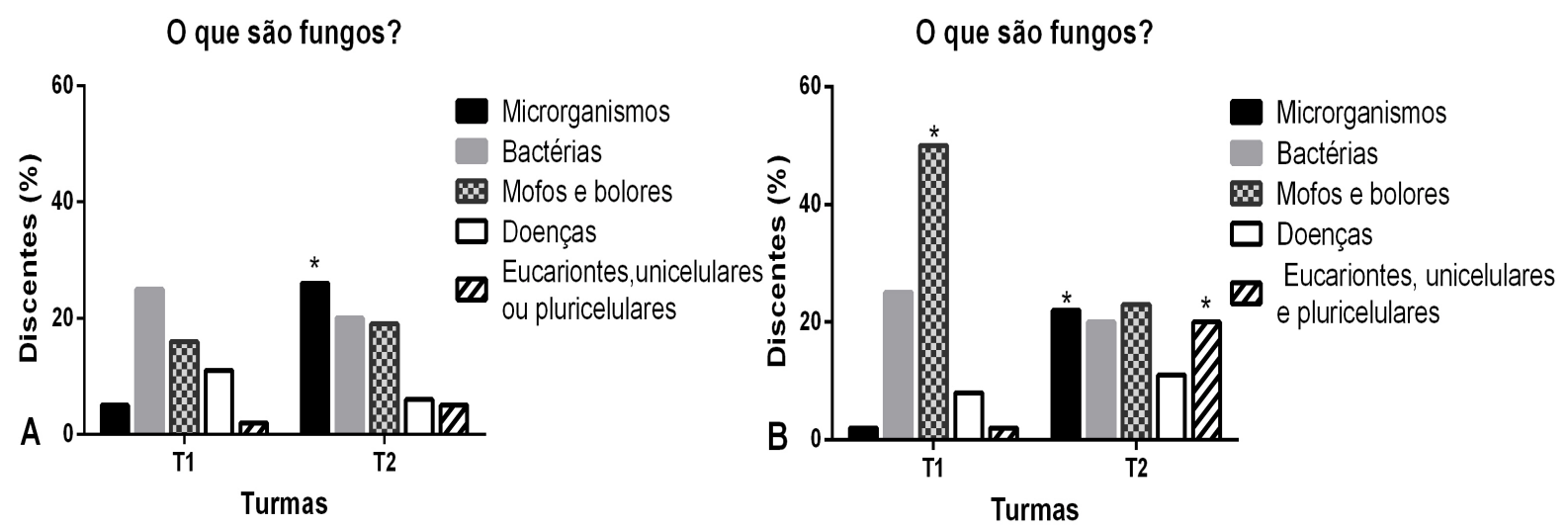

FIGURA 3. Percentual (\%) dos discentes quanto ao conceito de fungos. (A): Questionário inicial e (B) Questionário final. T1=Turma teórica e T2= Turma teórica e prática.

No questionário inicial sobre o conceito de protistas, $42 \%$ e $35 \%$ dos discentes respectivamente da T1 e T2 não responderam. Nas duas turmas também foi verificado associação com bactérias e fungos, além disto, foi citado que protistas eram causadores de doenças, sem especificar os tipos de doenças. Isto mostra a necessidade de abordagens que melhor contextualizem os papéis ecológicos e a patogênese provocada por alguns destes seres vivos. Somente $8 \%$ e $12 \%$ dos discentes de T1 e T2 respectivamente responderam de forma genérica que os protistas eram protozoários, sem menção as algas (Figura 4A). No questionário final, nas duas turmas houve redução da associação com bactérias, e ainda cerca de $30 \%$ dos alunos não responderam. Não houve diferença quanto ao conceito de protistas entre as turmas (Figura 4B).

A dificuldade dos discentes em caracterizar protistas assim como verificado para fungos pode estar relacionada com a diversidade morfológica e as dimensões dos representantes desse grupo, composto por protozoários e algas. A dificuldade de distinguir entre seres microscópicos e macroscópicos pôde ser notada por CASTRO (2012) investigando alunos do ensino fundamental I. Tais alunos categorizaram microrganismos com vermes, mosquito e pulga. Além de não distinguir conceitos funcionais entre os organismos. 

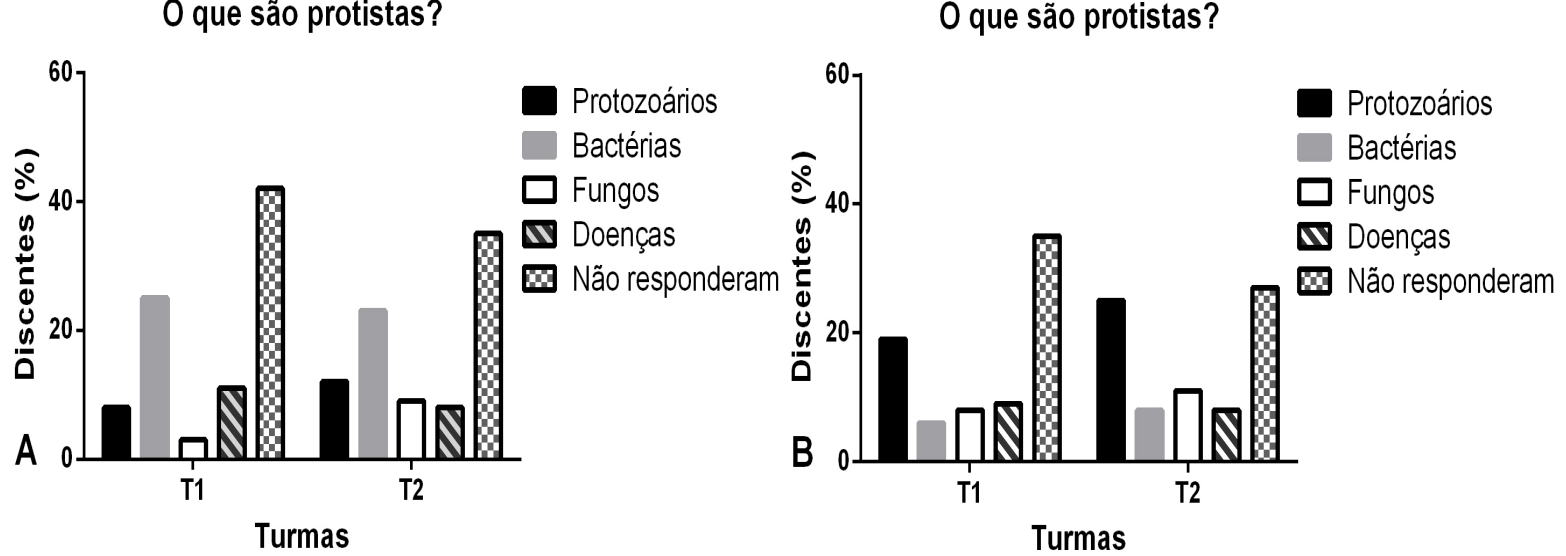

FIGURA 4. Percentual (\%) dos discentes quanto ao conceito de protistas. (A): Questionário inicial e (B) Questionário final. T1=Turma teórica e T2= Turma teórica e prática.

\section{Conhecimento sobre doenças causadas}

Em relação ao conhecimento prévio sobre doenças, os discentes da T1 e T2 citaram várias doenças, porém houve dificuldade em diferenciar viroses de doenças bacterianas ou vice-versa. Os principais tipos de doenças de origem viral citadas foram gripe, Síndrome da Imunodeficiência Adquirida (AIDS) e dengue. Quanto a doenças de origem bacteriana foi citada a leptospirose apenas na T2 (Figura 5A). No questionário final, na T1 e T2 permaneceram os mesmos relatos para doenças virais.

Para doenças bacterianas houve diferença para $T 2$ em relação $T 1$, pois não houve associação da gripe como doença causada por vírus. Para leptospirose também foi verificada diferença para T2, já que na T1 não foi citada esta doença (Figura 5B). A diferenciação entre doenças virais e bacterianas pela T2 foi um dado interessante, embora fatores individuais ou didáticos possam ter também influência nos resultados, a contribuição das aulas práticas neste progresso pode ser levada em consideração.
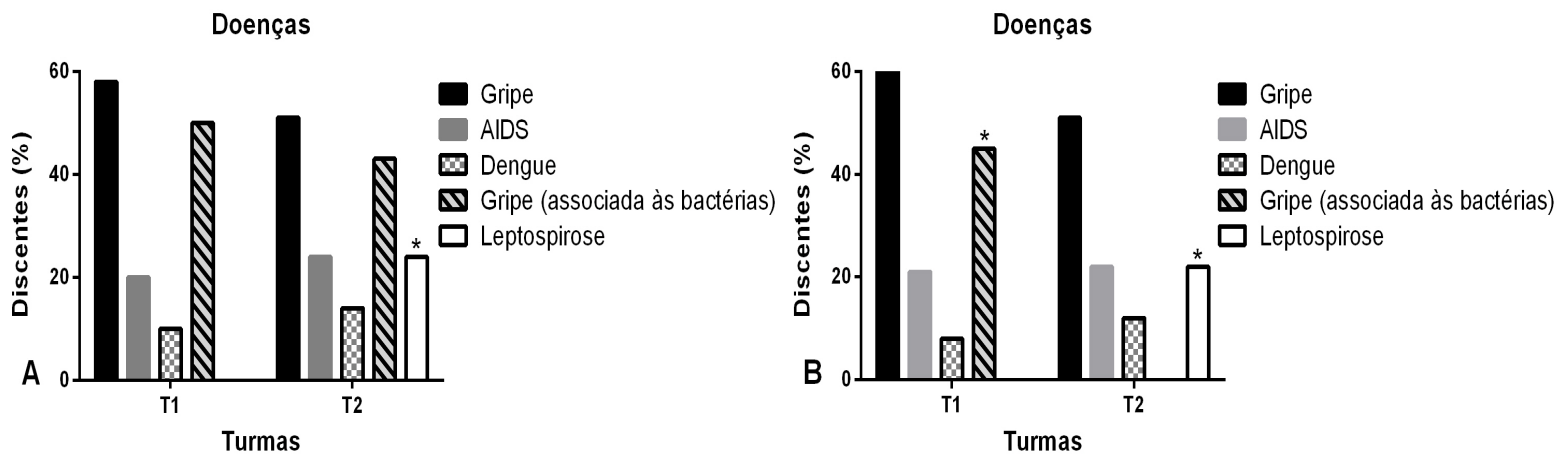

FIGURA 5. Percentual (\%) dos discentes quanto a doenças causadas por vírus e bactérias (A): Questionário inicial e (B) Questionário final. T1=Turma teórica e T2= Turma teórica e prática.

Para doenças causadas por fungos e protistas, os discentes das duas turmas continuavam com dificuldade para citar tipos de doenças causadas por estes organismos. Doenças causadas por protozoários e fungos acometem também um número considerável de pessoas. As principais doenças causadas por protozoários no homem são as leishmanioses, doença de Chagas, malária, toxoplasmose e 
amebíase (MACHADO et al., 2004). Já os fungos causam doenças conhecidas popularmente como micoses, a candidíase, por exemplo, é a mais universalmente distribuída (OLIVEIRA, 2014).

A dificuldade dos discentes em identificar doenças causadas por protozoários foram notadas em outros estudos. O conhecimento de discentes do ensino fundamental II sobre doença de chagas e leishmaniose visceral foi investigado respectivamente por VILLELA et al. (2009) e LOBO et al. (2013), estes autores constataram pouco conhecimento dos alunos sobre tais doenças, além de limitado conhecimento teórico e prático sobre medidas de prevenção

Quanto ao questionamento sobre os tipos de medidas para evitar doenças causadas por vírus, bactérias, fungos e protozoários, não houve diferença entre T1 e T2. Foram principalmente citadas medidas de higiene e vacinação, porém sem diferenciar quais medidas seriam adequadas especificamente para cada grupo estudado.

Esta abordagem geral sobre as medidas de prevenção pode ser consequência da dificuldade dos discentes em diferenciar as doenças. A falta de conhecimento sobre doenças são verificados em outros estudos, como por SILVA (2015), que avaliou alunos de ensino médio quanto à percepção sobre doenças sexualmente transmissíveis (DST). A maioria tinha pouca noção, porém, após o desenvolvimento de dinâmicas em grupo e aula expositiva sobre métodos contraceptivos foi observado aumento no percentual de alunos com conhecimento mais estruturado sobre DST e as formas de prevenção e tratamento. Com isto, o ensino das medidas de prevenção é um aliado importante no âmbito escolar, uma vez que os alunos podem levar estas informações para além da sala de aula. Para os conteúdos trabalhados nesta pesquisa, além das práticas desenvolvidas, outras abordagens deve ser considerada para possibilitar a distinção entre as doenças e seus respectivos agentes infecciosos, além da importância das medidas de prevenção.

\section{Metodologias práticas aplicadas e elaboração do manual de aulas práticas}

As aulas práticas realizadas na T2 transcorreram satisfatoriamente. Os discentes estavam bastante envolvidos, escutavam atentamente e participaram com empenho das atividades propostas. Em todos os conteúdos foram inseridos vídeos e imagens sobre a morfologia básica, doenças causadas e importância das medidas de prevenção. Para a aula prática sobre vírus, a turma foi orientada a confeccionar maquetes simples, demonstrando a estrutura básica dos vírus (Figura 6). Para esta atividade foram utilizados materiais fáceis de serem adquiridos e de baixo custo, como tubos do rolo de papel higiênico, palitos de dente, bolas de isopor, tinta guache, alfinetes, cola e tesoura. Nesta aula foi destacada a morfologia e principais doenças causadas por vírus, além de discutir sobre medidas de prevenção. 


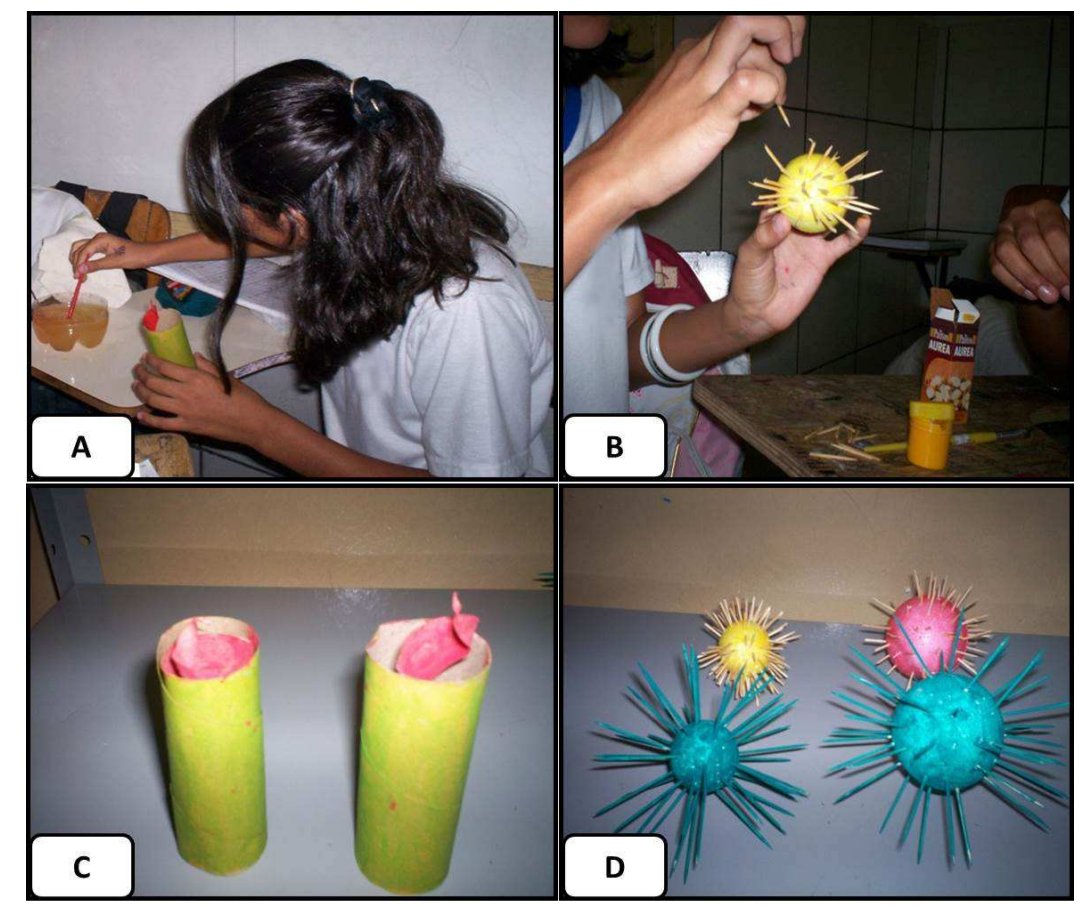

FIGURA 6. Construção das maquetes de vírus pelos alunos da T2 (A e B). Maquetes representando vírus que infectam plantas (C) e vírus infectam animais (D). (Fonte: Autores).

$\mathrm{Na}$ aula prática sobre bactérias, os discentes puderam acompanhar o desenvolvimento de colônias de bactérias. Um meio de cultura alternativo e de fácil preparo foi montado três dias antes da aula. Os ingredientes utilizados foram dois pacotes de gelatina incolor e uma xícara de caldo de carne (cozinhar a carne e peneirar para obter somente o caldo). Além disto, recipientes transparentes de plástico foram utilizadas como alternativa a placa de Petri. O modo de preparo consistiu em dissolver as gelatinas em dez colheres de sopa de água fria e misturar até homogeneizar. A mistura foi colocada em uma panela contendo uma xícara de caldo de carne. Após 15 minutos em fogo baixo, deixou-se esfriar o suficiente que permitisse colocar no recipiente de plástico, na altura de um dedo. Em seguida, o recipiente com o meio de cultura foi devidamente lacrado com tampa e colocado na geladeira, e deixado por aproximadamente três dias antes de usar. Este preparo serviu para preencher em média três vasilhas.

Os discentes utilizaram cotonete para criar diferentes fontes de contaminação como: chão, dentes, pés, mãos, dinheiro ou celulares. Logo após, os cotonetes foram esfregados levemente sobre o meio de cultura de forma retilínea e os meios de cultura foram etiquetados de acordo com o tipo de contaminação. As alterações foram acompanhadas no horário de intervalo das aulas de dois a três dias. Durante a aula foi enfatizado a morfologia bacteriana, importância ecológica, doenças causadas e a importância das medidas básicas de higiene (Figura 7). 


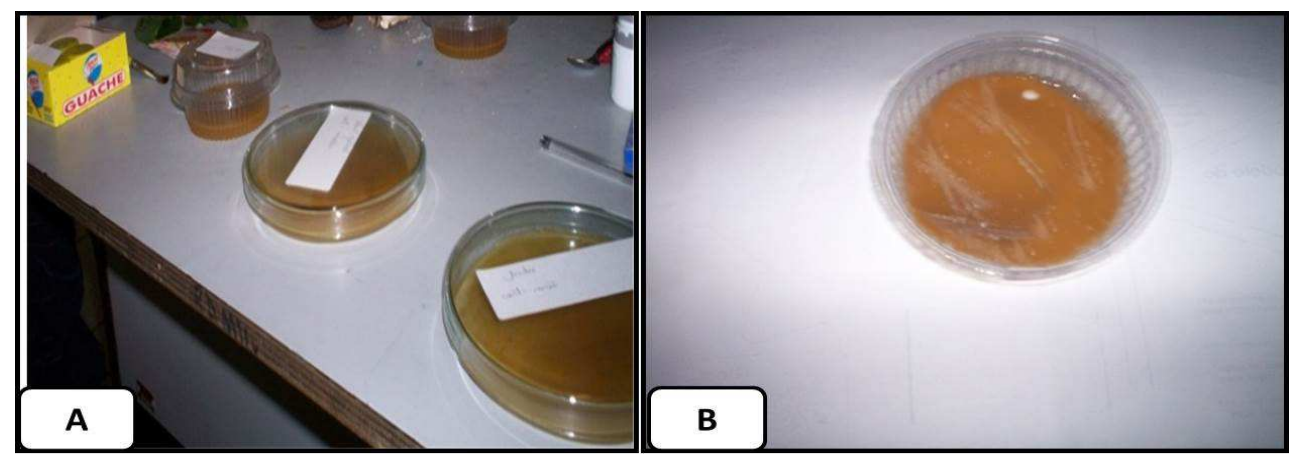

FIGURA 7. Meio de cultura alternativos em placa de Petri e vasilhas plásticas. Meios de cultura etiquetados com a forma de contaminação (A). Colônias de bactérias dispostas no meio (B).

$\mathrm{Na}$ metodologia prática sobre fungos, os discentes tiveram contato com alguns representantes como orelhas-de-pau, fungos presentes em plantas e alimentos em decomposição. Foi também realizado um simples experimento, no início da aula, utilizando-se levedura de fermento biológico. Colocou-se em um recipiente um copo de água, duas a três colheres de açúcar e um pacote de fermento biológico (Figura 8). Nesta aula foram ressaltados os papéis ecológicos dos fungos no meio-ambiente, o uso pela indústria, além de citar exemplos de algumas doenças causadas.

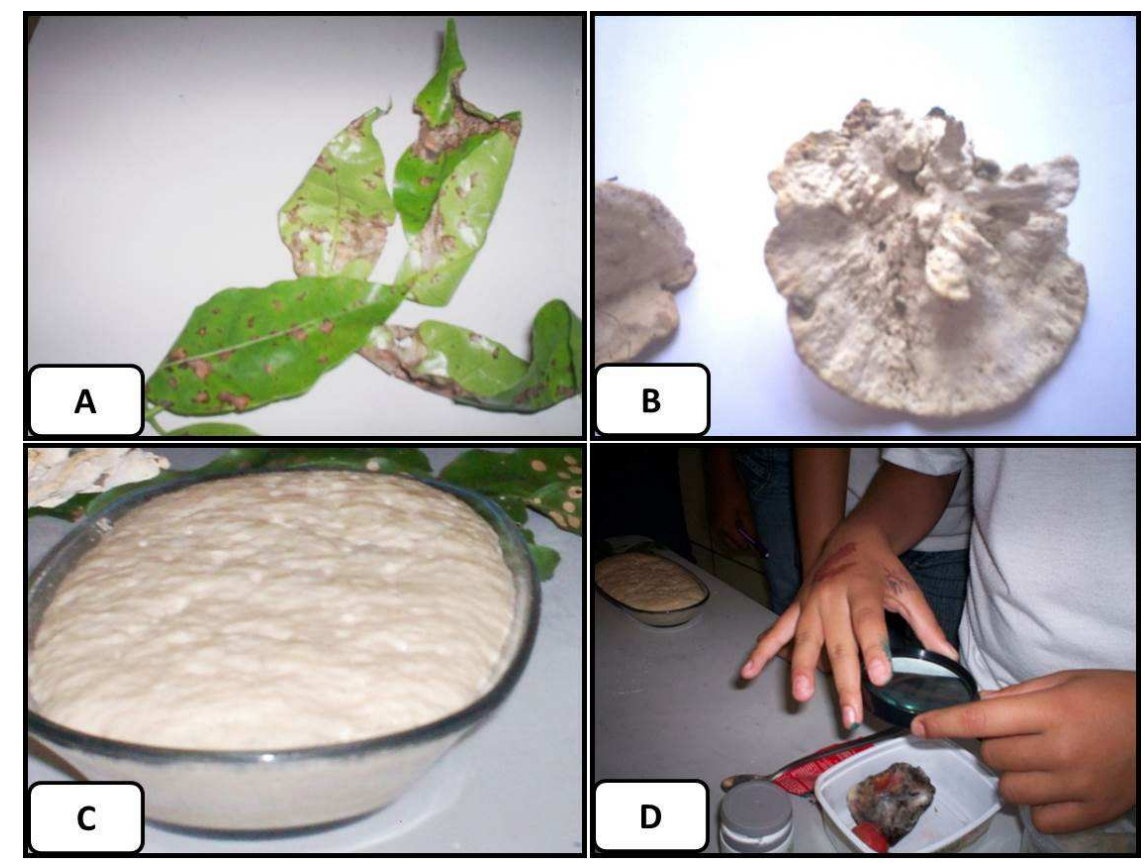

FIGURA 8. Tipos de fungos observados pelos discentes. Fungos de plantas (A), orelhas-de-pau (B), leveduras (C) e fungos em alimentos (D).

Para a aula de protistas os alunos foram incentivados a desenhar alguns representantes deste grupo com giz de cera ou tinta guache (Figura 9). Nesta aula foram destacadas características gerais dos protozoários e das algas, e doenças causadas por protozoários. 


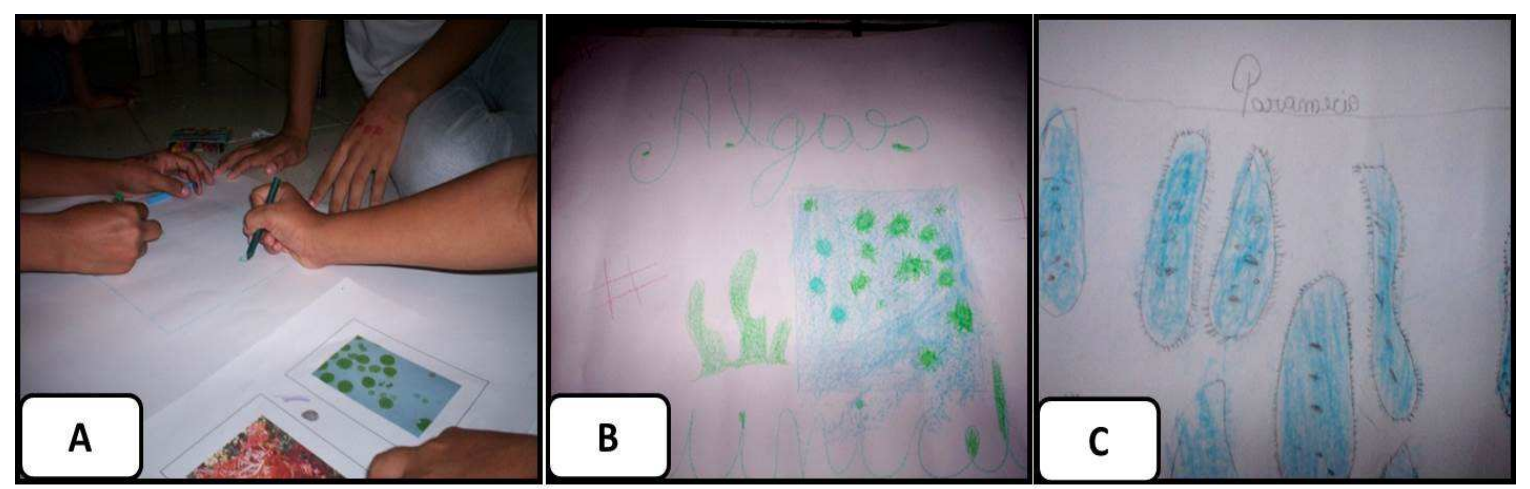

FIGURA 9. Desenhos e esquemas de protistas realizados pelos discentes.

Os discentes ficaram muito entusiasmados por estarem vendo algo diferente, e quando questionados sobre o que achavam das aulas práticas, observaram-se várias respostas positivas. O lúdico pode tornar as aulas de ciências mais envolventes, o que permite o uso do imaginário na construção do conhecimento. $O$ uso de modelos construídos com materiais alternativos pode ser também um estímulo ao aproveitamento de materiais recicláveis.

É importante ressaltar que os resultados gerados neste trabalho foram levados ao conhecimento da docente das turmas investigadas e dos demais professores de ciências do colégio, com o intuito de mostrar como metodologias alternativas simples em conjunto com aulas teóricas podem contribuir na estruturação de conceitos pelos alunos. Os docentes relataram que tinham interesse em aplicar aulas práticas, porém revelaram a necessidade de um laboratório para as práticas. A falta de material e o número de alunos em sala de aula também foram citados. Diante dos resultados observados, na conclusão da pesquisa, um manual contendo estas práticas e outras de baixo custo foi entregue a cada professor de ciências a fim de incentivar o uso em sala de aula das práticas propostas no manual ou a adaptação destas.

\section{CONCLUSÕES}

Este trabalho fornece indícios de que as aulas práticas sobre vírus, bactérias e fungos podem ter influenciado a mudança de conceitos verificados na turma com aulas teórica e práticas. Todos os métodos alternativos desenvolvidos na pesquisa foram pautados no incentivo ao uso de materiais de baixo custo e na importância das aulas práticas dadas em conjunto com as aulas teóricas. Estes dados podem guiar futuras investigações sobre quais aspectos precisam ser melhor desenvolvidos em sala de aula e quais abordagens podem ser utilizadas para melhorar o desempenho dos discentes nos conteúdos referentes a vírus, bactérias, fungos e protistas.

\section{REFERÊNCIAS}

ANDRADE, M. L. F.; MASSABNI, V. G. O desenvolvimento de atividades práticas na escola: Um desafio para os professores de ciências. Ciência \& Educação, v. 17, n. 4, p. 835-854, 2011. Disponível em: < http://dx.doi.org/10.1590/S151673132011000400005>. doi: 10.1590/S1516-73132011000400005.

BOAS, R. C. V.; MOREIRA, F. M. S. Microbiologia do solo no ensino médio de Lavras, MG. Revista Brasileira de Ciencia do Solo, v. 36, n. 1, p. 295-306, 2012. 
Disponível em: < http://dx.doi.org/10.1590/S0100-06832012000100030>. doi: $10.1590 /$ S0100-06832012000100030

BORGES, D.; TAUCHEN, G. Inovações no ensino universitário: possibilidades emergentes. Educação, Santa Maria, v. 37, n. 3, p. 555-568, 2012. Disponível em: <http://dx.doi.org/10.5902/198464445072 >. doi: 10.5902/19846444

BRASIL. Ministério da Educação. Secretaria de Educação Fundamental. Parâmetros Curriculares Nacionais: Ciências Naturais. Brasília, DF, 1998. 138 p.

CASTRO, D. R.; BEJARANO, N. R. O perfil de conhecimento sobre seres vivos pelos estudantes da coopec: uma ferramenta para planejar um ensino de ciências. Ensaio Pesquisa em Educação em Ciências (Belo Horizonte), v.14, n.3, p .261274, 2012. Disponível em: < http://dx.doi.org/10.1590/1983-21172012140316 >. doi: 10.1590/1983-21172012140316.

EUGÊNIO, T. J. B. Utilização de uma ferramenta multimídia para identificação de Artrópodes: avaliação de estudantes do Ensino Fundamental. Ciência \& Educação, v. 18, n. 3, p. 543-557, 2012. Disponível em: < http://dx.doi.org/10.1590/S151673132012000300004 >. doi:10.1590/S1516-73132012000300004.

GUARRO, J. Taxonomía y biología de los hongos causantes de infección en humanos. Enfermedades Infecciosas y Microbiologia Clinica, v. 30, n. 1, p. 3339, 2012. Disponível em: < http://dx.doi.org/10.1016/j.eimc.2011.09.006 >.

doi: 10.1016/j.eimc.2011.09.006.

HICKMAN, C.P.; ROBERTS, L.S.; LARSON, A. Princípios Integrados de Zoologia. Editora Guanabara Koogan S.A. Rio de Janeiro, 2016. 954 p.

LOBO, K.S. et al . Conhecimentos de estudantes sobre Leishmaniose Visceral em escolas públicas de Caxias, Maranhão, Brasil. Ciência \& Saúde Coletiva, v. 18, n. 8, p. 2295-2300, 2013. Disponível em: < http://dx.doi.org/10.1590/S141381232013000800013 >. doi: 10.1590/S1413-81232013000800013.

MACHADO, P. R. L. et al. Mecanismos de resposta imune às infecções. Anais Brasileiros de Dermatologia, v. 79, n. 6, p. 647-664, 2004. Disponível em: < http://dx.doi.org/10.1590/S0365-05962004000600002>.doi:10.1590/S0365 05962004000600002.

OLIVEIRA, J.C. Tópicos em Micologia Médica. 4ㅡㄹ edição. Rio de Janeiro; 2014.

SILVA, R. Quando a escola opera na conscientização dos jovens adolescentes no combate às DSTs. Educar em Revista, v.2, n. 57,p. 221-238, 2015. Disponível em: < http://dx.doi.org/10.1590/0104-4060.41170>. doi: 10.1590/0104-4060.41170.

TORTORA, G. J.; FUNKE, B. R.; CASE, C. I. Microbiologia, 10ª. edição. Porto Alegre: Editora Artmed, 2011. 
VILLELA, M. M. et al . Avaliação de conhecimentos e práticas que adultos e crianças têm acerca da doença de Chagas e seus vetores em região endêmica de Minas Gerais, Brasil. Cadernos de Saúde Pública, v. 25, n. 8, p. 1701-1710, 2009.

Disponível em: < http://dx.doi.org/10.1590/S0102-311X2009000800006 >. doi: 10.1590/S0102-311X2009000800006. 